\title{
Reformulação do ensino médico: Faculdade de Medicina e a USP
}

\section{O DESAFIO}

Estamos vivendo uma explosão dos conhecimentos com um imenso impacto sobre o presente e o futuro da Medicina. A maior parte dos atuais professores da Faculdade de Medicina deve estar perplexa com os avanços que nāo consegue compreender. Numa das maiores aventuras da Ciência o Homem seqüencia o seu DNA, localizando todos os genes, permitindo em muito breve não apenas fazer diagnósticos pré-natais de milhares de doenças genéticas, mas também prever susceptibilidade ao câncer e a outras doenças nãocongênitas. Esses professores podem ler nos jornais de domingo sobre terapêuticas gênicas mas não conseguem ler os artigos de revisão de Science e Nature e nem mesmo muitos dos artigos do New England Journal of Medicine. Não estão preparados para entender o que fez alguém receber o Prêmio Nobel de Medicina neste ano ou por que Science escolheu NO como a "molécula do ano". Abreviações crípticas da linguagem científica como PCR invadem a literatura clínica como armas de diagnóstico de paternidade e de doenças infecciosas. Receptores para hormônios e neuromediadores têm que ser conhecidos e clonados para entender-se endocrinologia, neurofarmacologia ou como funcionam os medicamentos. A imensa revolução da imunologia traz como potencial clínico dezenas de interleucinas, interferons e fatores de crescimento de subtipos de leucócitos que o microscópio não consegue identificar. Epitopos viram peptídios, que viram vacinas sintéticas que, por sua vez, atacam da hepatite ao AIDS, do Alzheimer - que ameaça a maior parte da população com idade para ser professor - às doenças auto-imunes.

Aoladodisso, a eletrônica introduz uma revolução paralela, onde foi possível substituir a primitiva laparoscopia por um exame direto de toda a anatomia do paciente, vendo nas telas todos os recantos doorganismo, incluindoo cérebro. Esta renovaçāomorfopatológica é bem mais fácil para o clínico ou cirurgião assimilar. Entretanto, é eticamente impossível conviver, hoje, com os avanços do diagnóstico, da medicina molecular, dos transplantes e novos procedimentos cirúrgicos, com uma Medicina que o cidadão e a Sociedade não podem mais pagar. Os dilemas e responsabilidades de dirigir o destino daquela que foi " $\mathrm{A}$ " Faculdade de Medicina, de um dos maiores hospitais do hemisfério, e a responsabilidade de assumir a educação médica de uma elite de estudantes que deverá exercer sua atividade profissional e liderança até 2050 deveriam tirar o sono de qualquer professor responsável.

Afastado, senāo alijado da velha Casa de Arnaldo(apesar do título de professor emérito, jamais tive acesso aos órgāos que devem traçar novas diretrizes), continuo a preocupar-me com minha alma mater à qual dediquei uma parte importante de minhas energias. 'A distância ouço com interesse que alguns estão conscientes dos dilemas e da necessidade de encontrar um novo papel para a secular Faculdade. Muitos, entretanto, nāo entenderam os eventos ocorridos à sombra da quartelada de Abril nem a evolução que transformou o conglomerado de escolas superiores na mais importante universidade latino-americana e,
ISAIAS RAW é professor emérito da Faculdade de Medicina da USP, tendo sido professor do MIT, Harvard School of Public Health e do Center of Biomedical Education do CUNY. É atualmente diretor do Instituto Butantan e do seu Centro de Biotecnologia. 
portanto, ainda sonham voltar o relógio na ilusão de que o prestígio voltará com o retorno ao modelo dos anos 30 .

\section{A FACULDADE, CENTRO DE INOVAÇÃO NOS ANOS 60}

Para discutir o futuroé importante saber para ondevai a Ciência e a Medicina, e, para situar-se nesse contexto, entenderpara onde a Faculdade se encaminhava nos 60 e quando perdeu seu rumo.

A inauguração em 1931 do edifício da Faculdade de Medicina de São Paulo foi ummarco fundamental para oensino médicono País. Com um significativo auxílio da Fundaçāo Rockefeller o edifício trouxe embutido o relatório de Abraham Flexner (1910) (1) que preconizava a formação científica na formação dos médicos (2) e ressaltava aimportância dos departamentosque fazem pesquisa científica original para uma escola médica e uma universidade. Foi então que surgiu o regime de tempo integral $\mathrm{e}$ de um hospital ligado à Faculdade para permitir o treinamento e a realização de pesquisas clínicas. Foram estas as conquistas que transformaram nossa Faculdade na primeira "South of the Equator", a ser incluída (por algum tempo) pela American Medical Association como padrão A.

O panorama das ciências básicas era estreito. No luxuoso edifício, cada catedrático tinha pelo menos meio andar, um anfiteatro para suas aulas (o regulamento restringiả as aulas teóricas ao catedrático)e até uma ante-sala, onde se isolava para preparar suas aulas magistrais. Bastavam oito departamentosbásicos: anatomia, histologia e embriologia, anatomia patológica, parasitologia, microbiologia, fisiologia, farmacologia e química biológica e físicoquímica.

Quinze anos mais tarde, interessado em aprender a pesquisar, ingressei na Faculdade. A anatomia continuava fiel ao Chiarugi, incluindo suas notas de rodapé, e ocupava o equivalente a um ano inteiro do curso médico. Os demais cursos eram tradicionais, apesar de que no Primeiro Mundo os autores ingleses e americanos começassem a impor seus tratados como novos conteúdos: Maxwell e Bloom na histologia, Best e Taylor na fisiologia, Goodman e Gilman na farmacologia.

Ainda aluno de segundo ano, e monitor, estimulado pela visão de Jaime Cavalcanti, dei as primeiras aulas sobre uso biomédico de isótopos e ação biológica das radiaçōes, iniciando a substituição de um livro de físico-química do início do século pela biofísica. A química do sangue e urina que dominava o curso de química fisiológica deu lugar, em aulas e seminários, à bioquímica e ao metabolismo celular. Em 1951 L.C.U. Junqueiravoltava da Escola Paulista de Medicina (para onde, como estudante, fora "exilado" pela mediocridade do então professor de patologia) e iniciava, como novo professor de histologia, uma biologia celular moderna. Nesse ano, já nomeado assistente, pude criar o Laboratório de Enzimologia que iniciava pesquisas em metabolismo celular usando um Warburg e um espectrofotômetro que, por anos, jamais haviam sido utilizados. Nossos dois departamentos e parte da fisiologia ganharam o apoio da Fundação Rockefeller que neles via a recuperação das ciências básicas. Em 1958, quando João Aguiar Pupo era diretor, conseguimos a primeira alteraçāo curricular, trazendo para o currículo médico, na Bioquímica, a genética médica (que havia nascidonaFaculdade, com André Dreyfus, mas fora expulsa quando este e outros tentaram construir um novo andar para abrigar a Faculdade de Filosofia, Ciências e Letras, que criara então, em volta da Medicina, a Universidade de São Paulo).

Nos anos 50 e 60 inicia-se a explosão das ciências biomédicas básicas. $\mathrm{O}$ empirismo da "arte médica" começa a sofrerum impactodas modernas pesquisas. $\mathrm{O}$ estudo do metabolismo intermediário, o isolamentode centenas de enzimas que dele participam, a descoberta de como vitaminas, hormônios ealguns medicamentos atuam fez com que a bioquímica invadisse a fisiologia, farmacologia, biologia celular e patologia. Enquanto os bioquímicos colecionavam prêmios Nobel, os compêndios aumentavam de tamanho a cada ano. $\mathrm{O}$ artigo de Watson e Crick, que nem mesmo ocupou uma página toda do Nature, ainda não tinha um impacto significativo sobre o ensino médico. A American Medical Association publicava no Time um anúncio promocional da classe, onde um imenso robot feito de livros e com estetoscópio transmitia a idéia de que ser médico era ler milhares de páginas de livros-textos. Se a nossa Congregação tivesse se dado ao trabalho de empilhar os textos adotados, descobriria que 12 horas por dia, durante os três anos dos cursos básicos, não eram suficien- 


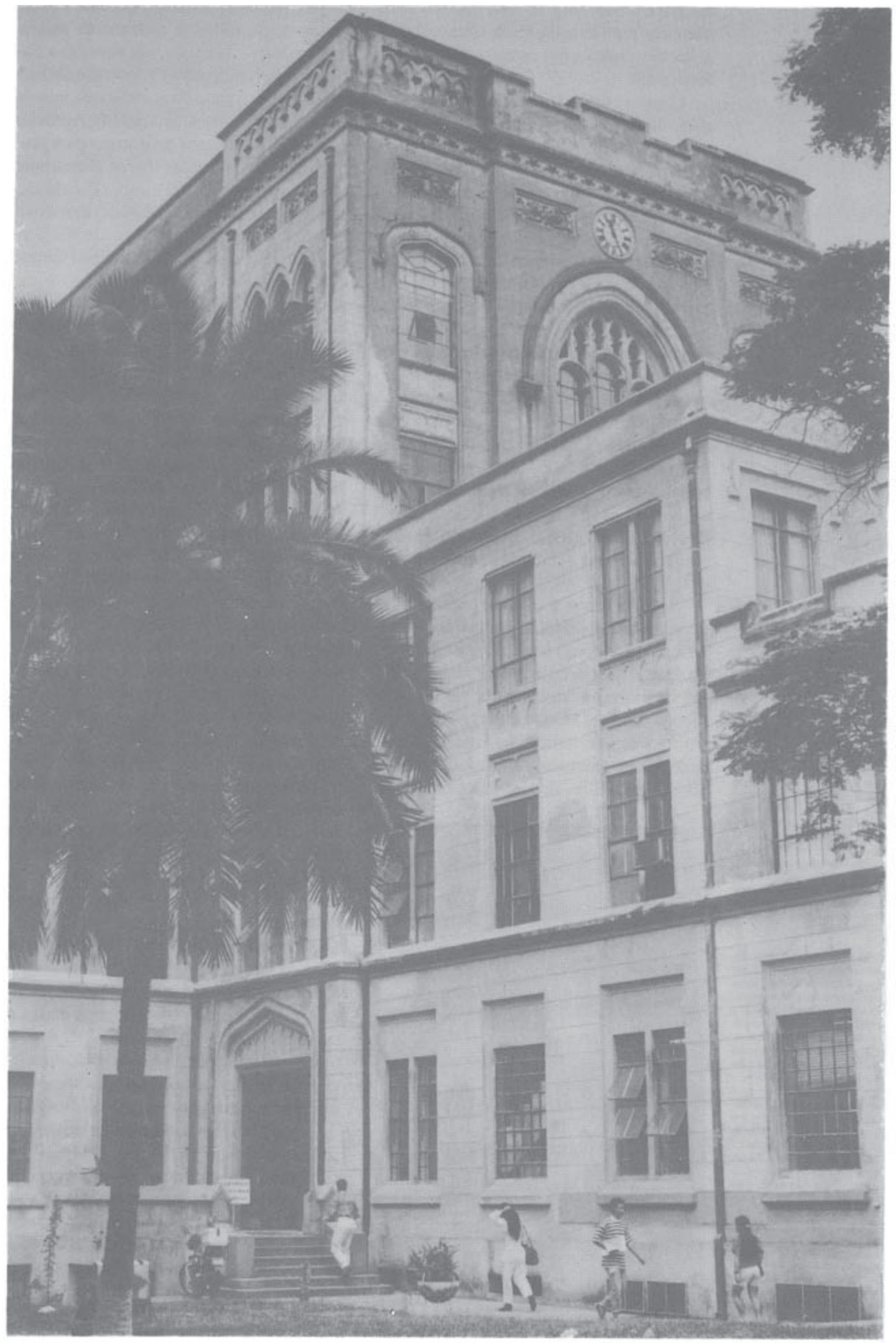


3 Paul Ehrlich, um dos génics que contribuiu para desertvol. ver a imunclogia e imventou a quimioterapla, prêmio Nobel de Medicina em 1908, quase abandonou a Faculdade de Medicina quando descobriu que tinha que decorar cerca de 6.000 novos termos. Em com estudantes da Escola Médica de Harvard mostrou Médica de Harvard mostrou era um dos principais fasores para que os estudantes mais inteligentes abandonassem a escola.

4 Uma atitude geral do sistema universitário oficial que, ao simplesmente fechar suas portas a mais alunes, compar. tilha com o crime de permitir a prolferacalo de escolas "supe-

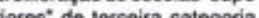
menos preparados e com re. cursos familiares mais reduzi. dos, os penaliza a pagar para serem profissionais de terceira categoria. Em 1964, um dos argumentos, numa ampladio Silva a Faculdade para pedir aumento de vagas, 6 que nåo havia mais cadáveres đisponiveis para ensinar anatomial

5 Nas quais tive alouma partici. pecâo, como membro do Con. seiho que instrutu a Faculda. de de Medicina da UnB, e membro da Comissáoque ins. tituinu a Universidade de Campinas. tes para lê-los uma só vez, quanto mais competir com os rodapés do Chiarugi para achar neurônios a fim de memorizar novos termos (3).

O quarto andar da Faculdade de Medicina, onde ficava a bioquímica, transformou-se num importante foco de inovação, de onde saíram as grandes renovações do ensino de ciências nas escolas secundárias, e o vestibular unificado que trouxe à Faculdade os melhores candidatos que já sabiam oque era metabolismo intermediário, ATP, ciclo de Krebs e a estrutura do DNA. Não havia mais possibilidade de tentar remediar introduzindo novas disciplinas. Os avanços não eram só intradepartamentais, mas interdepartamentais, onde os conhecimentos borravam os limites das cátedras. A reformulação do currículo médico era considerada, pela Congregaçāo, uma invasão nos domínios dos catedráticos que nem mesmo procuravam evitar a redundância $\mathrm{e}$ omissōes das três clínicas médicas ou das três cirúrgicas (todas querendo ensinar megacólon mas nenhuma apendicite aguda).

Aproveitamos a imensa pressão existente por maisvagas. Osnumerososclausus, introduzidos como parte do acordo com a Fundação Rockefeller, têm até hoje uma importância fundamental que garante condiçōes mínimas à Universidade. Ao contrário dos sistemas francês, italiano, argentino emexicano, a matrícula limitada obriga uma adequação entre, de um lado, condições

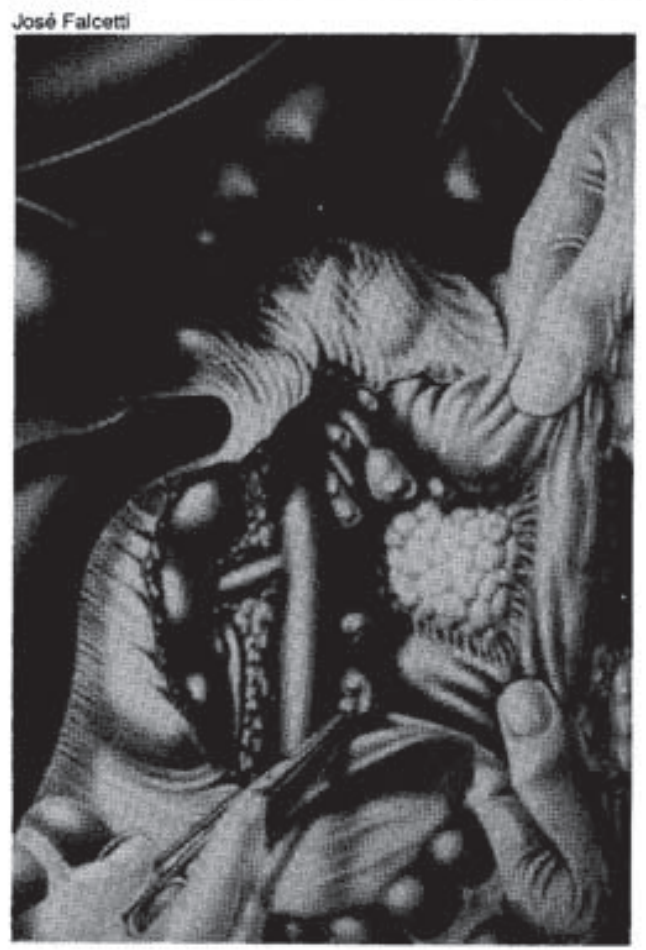

físicas, tamanho do corpo docente e orçamento e, do outro, o número de alunos matriculados. Todavia, nos anos $60 \mathrm{a} \mathrm{Fa}$ culdadese desobrigava da demanda de mais vagas, não por parte dos candidatos, mas da sociedade, por mais médicos (4). Aproveitamos a demanda por mais vagas para propor uma alternativa: acolher os alunos num outro curso médico, da mesma Faculdade, e que teria uma outra finalidade: a de experimentar inovaçōes do currículo médico. Essa idéia, levada pelo prof. Ulhoa Cintra, entâo secretário da Educação, ao governador AbreuSodré, recebeu sua imediata aprovação. A Faculdade eximiu-se de receber mais alunos e de inovar, mas permitiu, a contragosto, que um grupo de seus docentes usasse essa oportunidade para inovar.

O curso experimental de Medicina autorizado em novembro foi instalado em março, e para a surpresa da Casa de Arnaldo foi preferido por mais de $90 \%$ dos alunos melhores colocados no vestibular! Foi uma imensa improvisaçāo usando-se, nos horários disponíveis, salas e laboratórios da Cidade Universitária. Não houve recursos para adquirir equipamentos ou construir(só três anos mais tarde concretizou o Hospital Universitário que lhe era destinado). Apesar de sua improvisaçāo (o curso era "inventado" em reuniōes semanais noturnas, quando discutíamos o conteúdo dos temas da semana $\mathbf{e}$ as idéias trazidas, particularmente por Alípio Correia Neto, sobre a formação do médico para servir à comunidade) e de recursos irrisórios, logrou implantar o que não conseguiram as então novas faculdades de Medicina da Universidade de Brasília e da Unicamp (5). O espírito inovador estava adormecido na Casa de Arnaldo.

O curso experimental introduziu uma série de idéias:

a) era indispensável integrar medicina clínica e social desde os primeiros anos do curso médico;

b) o curso não poderia ser dividido em disciplinas artificiais, que nāo contemplavam o contínuo entre o que eram as oito cadeiras do curso tradicional, e a ciência biomédica se desenvolvia;

c) os alunos deveriam aprender a aprender, o que não se logra em aulas teóricas ou repetindo experiências estereotipadas, mas nos livros e revistas, na biblioteca e nos laboratórios em contato com pesquisadores ativos;

d) para o nível do corpo docente atingir o 


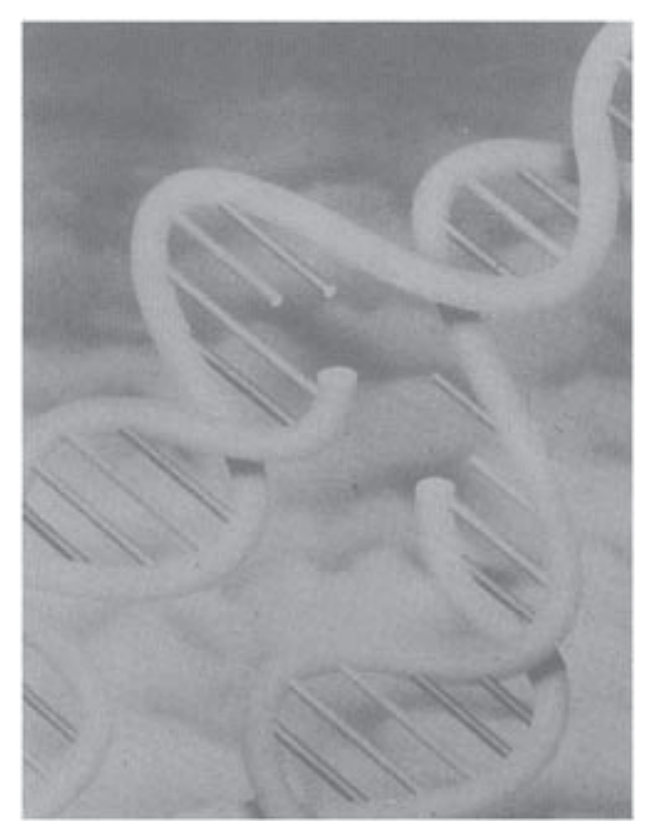

dos grandescentros de pesquisas biomédicas é necessário uma massa crítica e a interação com especialistas de formação diversa: a integraçăo das cadeiras básicas na Cidade Universitária e a çriaçăo de uma verdadeira Universidade era fundamental;

e) o ensino médico exige não apenas um hospital terciário, mas o contato do aluno com o paciente nāo-hospitalizado e com a realidade da medicina dodia-a-dia. Para isto deve utilizar também um hospital que serve auma comunidade e nāoaos casos "interessantes" do País, onde o aluno nãoé mão-deobra mas estudante, e um posto de saúde (até hoje mantido junto ao Butantan, mas que já existia, de forma ainda primitiva, quando a Faculdade de Higiene era parte integral da Faculdade de Medicina e participava do curso médico);

f) inovação não é "uma" reforma curricular mas um processo contínuo de adaptação criativa ao desenvolvimento da pesquisa $e$ da medicina.

AFaculdade de Medicina foi incapazde reconheceroCursoExperimental comosua extensão e, temendo seu evidente sucesso, cometeu um infanticídio (sequer consta da publicação que comemora o seu centenário), perdendo a primazia de ser a única Escola Médica no mundo que criou um centro experimental de educação médica no qual deveria experimentar e irradiar novas idéias para o sistema de escolas médicas do País e do continente. Restou bastante, e não é infreqüente que se encontre em ex-alunos em posição de destaque que informam orgulhosos que foram do "expe- rimental" (6). Restou também a Universidade de São Paulo, que ganhou com a formação de importantes grupos de pesquisas liderados pelos docentes oriundos da $\mathrm{Me}$ dicina. É com orgulho que assinalo que no Departamento de Bioquímica, que foi avaliado como o melhor da USP (na primeira fase da avaliação externa), estāo ou passaram para outras unidades, entre outros pesquisadores de peso, cinco dos meus ex-assistentes, hoje professores titulares.

\section{INOVAR OU MEDIOCRIZAR-SE}

Nos anos 60, para nós, que construímos o curso experimental, o desafio de inovar o ensino médico era parte do orgulho de pertencer "A" Faculdade de Medicina, ao invés de dormir no berço esplêndido que o padrão Ada AMA representou. Estávamos entre os primeiros do mundo. Só em 1966 ocorreu a conferência de Endicott que, entre outras coisas, deu origem à inovação da Case Western Reserve(7). As experiências deHamilton(Canadá), Maastrich(Holanda) e Ben Gurion (Israel) só se iniciaram nos anos 70. Harvard tentou em 68(8) e só nos 90 sua reforma começou a criar raízes.

Abraham Flexner descreveu sua visão de educaçāo médica como: "Por conveniência, o currículo médico pode ser dividido em duas partes, de acordo com o trabalho que deve ser conduzido principalmente nos laboratórios ou no hospital, mas a distinção é apenas superficial, porque o hospital é no sentido pleno um laboratório". Esta divisão, que não devia ter ocorrido, cindiu de fatooensinomédico(9)e a Fundaçāo Robert Wood Johnson estabeleceu uma comissão com a função de promover a integração do ensino num único ambiente de educação médica. Em 1990 concedeu um auxílio a doze escolas médicas (entre as quais Columbia, Hawaii, John Hopkins, Kentucky, Oregon, Rochester e Yale) para fazer uma revisão de seus curricula para integrar as ciências básicas e clínicas.

A Robert Wood Johnson Foundation acaba de elaborar um novo relatório (10), que terá um impacto igual ao do relatório Flexner. Deve ser lido e estudado pela Congregação da Faculdade. Suas recomendaçōes gerais são:

1)As escolas médicas devem assegurarque seus programas integrem as ciências (básicas)da prática médica durante todo o curso. 2) Além do conhecimento científico, o médico deve ter uma compreensāo dos as-
6 Um paralelo impressionante existe com os ex-alunos do Colf́gio de Aplicaçato tamberm extinio esterilizado com sal a Egide do regime militar.

7 'Medical Education Reconsidered, Report of the Endioct House Summer Study on Medical Education: July/ 1965. Esta conterência foi dirigida por Oliver Cope entáso do Massachusetts General Hospital e depois General Surgeon dos Estados Unidos. eprot. Jemold Zaccharias, professor de Fisica do MIT e que foi responsatvel polas grandes inovaçóes no ensino do Clânclas para escolas socundtiticias para escolas secundarias, com impacto mundial. Isto ça univorsitária, náo-médica empromover o avanço da edu. caçấo múdica. Uma segunda conferelncla teve lugar no ano seguinte sobre o papel das seguinte sobre o papel das ciencias do comportamento Cope e Zaccharias se associaram a Bond, do Departamento de Psiquiatria da Western Reserve University School of Medicine. para produzir um relatorio com o titulo Man Mind \& Medicine: the Doctor's Education.

8 Um dos relatos está no Views of Medical Education and Medical Care, editado por John H. Knowles que deixou a Fundaçăo Rockefeller, para dirigir o Massachusetts General Hospital. Zaccharias 6 novamente um dos indutores.

9 Rarissimamente, enquanto vi. vi na Faculdade de Mecicina, alguém do hospital cruzou a avenida, salvo para as reunióos de Congregaçáo, ou cirurgibes para ir à Anatornia o at Técnica Cirúrgica.

10 Commission on Medical Education: The Sciences of Medical Practice. Modical Education in Transition, A. Q. Marson and R. M. Jones. editors. Princeton, New Jorsey. The Robert Wood Johnson Foundation, July/ 1992. 
11 A partir dos anos 70 começa. ram a surgir nos Estados Uni. dos, como na Inglaterra, taculdades de Medicina de seis anos. Entre 1975 e 1979 ful professor de Bioquimica e Nu. triçấo na City University of New Yack panedocorpo do. cente que iniciou um destes cursos.

12 Isaias Raw, 'An Intermarican Effort to Innovate Medical Education , in American Journal of Medical Education 52. 654, 1977

13idem, Avamia trom Moloculos to Modicine, Boston, Little Brown, 1975

14 D. C. Tosterson, "New Pathways in General Medical Education", in New England Journal of Medicine 322:234. 1990 pectos comportamentais e sociais da saúde e da doença. A educação médica deve incluir ciências do comportamento, sociais, probabilísticas e de informação, além da ética.

3) As escolas médicas devem expandir o contexto do treinamentoạlém dos hospitais de cuidados terciários, para incluir, por exemplo, cuidados ambulatoriais, hospitais comunitários, casa de repouso e creches. A educação médica deve incluir o aprendizado de experiências que prepare os estudantes para o exercício profissional em comunidades onde as barreiras para o acesso (aos cuidados médicos) é mais evidente. O corpo clínico deve preparar os estudantes para entender o curso longitudinal de uma doença e sua base científica, e enfatizar os problemas crônicos de longo prazo que fazem com que os pacientes procurem atenção médica continuada.

4) Para exercer suas atividades na avaliação do progresso acadêmico dos estudantes, a Faculdadede Medicinadeve incorporaruma avaliaçâo efetiva dos procedimentos e técnicas que sāo compativeis com seus objetivos educacionais. As ciências (básicas) da prática médica não podem ser efetivamente integradas durante o programa educacional médio a menos que existam procedimentos complementares para esta integração.

5) Para implementar as resoluçōes acima, cada escola deve ter uma organizaçăo com autoridade apropriada, cuja liderança é respeitada comorepresentandoomaisaltonível acadếmico. Essa autoridade deve ser responsável pelo planejamento, implementação, monitoração, avaliaçăo e revisão do programa educacional, revendo, se necessário, e premiando a excelência no ensino.

Estas recomendaçōes não refletem a riquezade idéias e conceitos do relatório, cuja implicação para nós fica limitada pela existência, nosEstados Unidos, do College, onde se ensina parte do curso básico (11).

\section{UM MODELO DE INTEGRAÇÃO}

Montar um curso médico em alguns meses não permitiu um esforço mais organizado. Em minha experiência com as tentativas de reformulação do ensino de ciências nas escolas secundárias do País aprendi que, para introduzir uma nova filosofia e um novo conteúdo, é preciso preparar novos livros.

Apesar de discutirmos em detalhe, em uma reuniāo semanal, as aulas do curso experimental refletiam basicamente os livros da época, que se tornavam de fato o currículo.

Discutimos horas a fio a integração das ciências básicas e a introdução da medicina clínica e social. Todavia ao adotar os mesmos compêndios, voltamos, em parte, para os cursos tradicionais.

Afastadododia-a-diae "promovido"em 1970 a professor do MIT, tive tempo para pensar em maior profundidade o desafio de criar um currículo médico integrado. Surgiu a idéia de centrar o currículo em um pequeno número de doenças ou síndromes, que ofereçam um ponto focal para a integração. O uso desses pontos focais oferece temas que, por sua relevância, motivam os estudantes.

Essa proposta de projeto foi publicada (12), e apresentada à organização Panamericana de Saúde, que deu um auxílio ao MIT, permitindo a publicação de um primeiro texto experimental:Anemia: from Molecules to Medicine (13). Seus capítulos são: 1 . Investigando a hemácia; 2. Das moléculas à funçāo; 3. Das moléculas à doença; 4. Das moléculas à genética e 5 . Dasmoléculasà informaçāo. Extremamente estruturado do ponto de vista educacional cada capítulo é precedido por uma definição dos objetivos a ser dominados, sugestôes de experiências de laboratório básicas e clínicas, enquetes, transcrição de artigos clássicos (ao invés de todos os alunos tentarem buscar as mesmas revistas) e dados experimentais de artigos para interpretaçăo. Idéias semelhantes surgiram mais tarde nas escolas de McMasters e BenGurion, mas não levaram à preparação de textos.

$\mathrm{O}$ esforço criativo não pode ser individual. Exige, como os grandes projetos de renovação de ensino de ciências, uma equipe do mais alto nível, que sabe para onde estāo caminhando as ciências básicas; clínicos e cirurgiōes que acompanham estes desenvolvimentos, especialistas em ciências do comportamento e informática. Em artigo recente (14), Tosterson, da Faculdade de Medicina da Harvard, assim descreve: "Éminha opiniāoque uma reforma substancial da educação médica requer a criação de uma organização de docentes interdisciplinar, interdepartamental e finalmente interfaculdadese inter-universidades, com responsabilidade $\mathrm{e}$ autoridade para desenvolver e acompanhar este programa". Obviamente uma tarefa nobre, fundamen- 
tal, e que justificaria recolocar uma Faculdade na posição de líder.

\section{UM ESQUEMA DE INTEGRAÇĀO}

Em nossa proposta à OPAS demos um possível exemplo do uso de focos de interesse para criar um curso básico destinado e exclusivo para estudantes de Medicina, que integra ciências básicas, iniciação à clínica e à medicina social. É possível imaginar um número de variantes, e uma possibilidade seria: mas, saltando a parte básica, exigiu que docentes de cada disciplina estivessem presentes nas aulas-seminários, criando uma proporçâo maior de docentes do que de alunos.)

Tanto na concepção como nos módulos do curso participariam docentes dos institutos básicos da Universidade, criando assim uma integração total no âmbito de ensino entre Faculdade e Instituto. Para participar destes cursos seriam mobilizados médicos e não-médicos que se sentissem confortáveis com os temas médicos, uma vez que

\begin{tabular}{|c|c|}
\hline PONTO FOCAL & TEMAS ABORDADOS \\
\hline Má nutriçāo & $\begin{array}{l}\text { O homem como um comportamento em } \\
\text { equilibrio quimico e energótico: } \\
\text { bioenergética, nutriçőo e } \\
\text { desenvolvimento, implicaçōes sociais. }\end{array}$ \\
\hline Multitrauma & $\begin{array}{l}\text { Introduçōo à anatomia macroscópica, } \\
\text { choque, regulaçăo do volume } \\
\text { extracelular, coagulaçâo. }\end{array}$ \\
\hline Anemia & $\begin{array}{l}\text { Proteinas como base da estrutura e } \\
\text { funçăo, macromoléculas e a informaşăo, } \\
\text { doenças moleculares e doenças hereditárias. }\end{array}$ \\
\hline Diabetes & Metabolismo e sua regulaşão e receptores. \\
\hline Gravidex & $\begin{array}{l}\text { Reproduçŏo, gravidex, desenvolvimento, } \\
\text { fortilidade e esterilidade, problemas } \\
\text { populacionois. }\end{array}$ \\
\hline Diarrbia & $\begin{array}{l}\text { Equilibrio de água e sal, regulaşăo do } \\
\text { pH, compartimentos. Aspectos sociais. }\end{array}$ \\
\hline Infarto & Fisiologia da circulaçáo, hipertensâo. \\
\hline Côncer & $\begin{array}{l}\text { Carcinogênese, quimioterapia, mecanismo } \\
\text { de açāo de drogas, resistência às drogos. }\end{array}$ \\
\hline Neurose & Psicossomatixą̧ōo, psicofórmacos. \\
\hline
\end{tabular}

Propomos que o primeiro esforço deva ser o de definir uma série de unidades como as propostas acima, formando grupos que discutam a fundo e elaborem os textos. A criaçăo de textos pelas escolas médicas é usual (a própria Faculdade de Medicina de Harvard distribui "apostilas"). O que nunca foi feito é um esforço coletivo de inovaçāo metodológica de conteúdo e de integração. Estesnovos textos seriam a base de um curso integrado básico-clínico-social.

O texto reflete uma integração cuidadosamente concebida. Tendo os materiais de aprendizagem prontos, a criação de um curso integrado é um processo mais simples. Estes textos multidisciplinares seriam utilizados pelos alunos e pelos professores encarregados das partes que compõem cada módulo. (A experiência da Western Reser$\mathrm{ve}$, que integrou o ensino a partir de siste- existem nos institutos pesquisadores que se dedicam em profundidade a temas médi$\cos$. Naturalmente estes cursos seriam privativos de estudantes de Medicina. Com a integração proposta não haveria uma duplicação do corpo docente, nem se consolidaria uma cisão entre Universidade e Faculdade (15).

Um esforço sério na criação de inovaçōes profundas é tão importante quanto outras pesquisas que a Faculdade deve conduzir. Elas não podem parar nos cursos básicos, mas devem incluir um esforço sério no ensino da clínica, que certamente abrangeráo impacto da informática tanto na organização do aprendizado quanto na substituição das informações limitadas e desatualizadas ministradas atualmente por aulas teóricas transformando tanto o ensino quanto a prática da medicina.
15 Gostaria entretanto de doixar claro que, a meu ver, a cooperaçầo em cursos e pesqui. sas cientificas entre os Insti. tutos e a Faculdade nâo excui a existéncia de laboratocili axistancia de laboratoprosulsasclinicas em profundidade o que exigem a participaçáa de pesquisado res treinados e en regime de dedicaçâo exclusiva $\mathrm{O}$ pri. meirodocentendo-médico toi contratado no Departamento de Bioquimica quando prot. de Bloquimica quando o prot. cavia Pupocra diretor. To. davia é preciso caracteriza que so existirào pesquisado res năo-médicos quando eles forem tratados como tal, enáo como "colaboradores" técni. cos dos clinicos. Pesquisa ciomédicando ó. nos paises biomedca nâse vais avancados, precrogativa de médicos, mas de pes. quisadores competentes com idelas originais. Ensaios clínicos 6 que sảo prerrogat: va dos médicos. 